\title{
Time domain simulation of chatter vibrations in indexable drills
}

\author{
Amir Parsian ${ }^{1,2}$ [D $\cdot$ Martin Magnevall ${ }^{1,2} \cdot$ Mahdi Eynian $^{2} \cdot$ Tomas Beno $^{2}$
}

Received: 26 February 2016 / Accepted: 4 July 2016 / Published online: 22 July 2016

(C) The Author(s) 2016. This article is published with open access at Springerlink.com

\begin{abstract}
Regenerative chatter vibrations are common in drilling processes. These unwanted vibrations lead to considerable noise levels, damage the quality of the workpiece, and reduce tool life. The aim of this study is to simulate torsional and axial chatter vibrations as they play important roles in dynamic behavior of indexable insert drills with helical chip flutes. While asymmetric indexable drills are not the focal points in most of previous researches, this paper proposes a simulation routine which is adapted for indexable drills. Based on the theory of regenerative chatter vibration, a model is developed to include the asymmetric geometries and loadings that are inherent in the design of many indexable insert drills. Most indexable insert drills have two inserts located at different radial distances, namely central and peripheral inserts. Since the positions of the central and peripheral inserts are different, the displacement and thereby the change in chip thickness differs between the inserts. Additionally, the inserts have different geometries and cutting conditions, e.g., rake angle, coating, and cutting speed, which result in different cutting forces. This paper presents a time-domain simulation of torsional and axial vibrations by considering the differences in dynamics, cutting conditions, and cutting resistance for the central and peripheral inserts on the drill. The time-domain approach is chosen to be able to include nonlinearities in the model arising from the inserts jumping out of cut, multiple delays, backward motions of edges, and variable time delays in the system. The model is used to simulate cutting forces produced by each insert and responses of the system, in the
\end{abstract}

Amir Parsian

amir.parsian@sandvik.com

1 AB Sandvik Coromant, SE-811 81 Sandviken, Sweden

2 University West, SE-461 86 Trollhättan, Sweden form of displacements, to these forces. It is shown that displacements induced by dynamic torques are larger than those induced by dynamic axial forces. Finally, the vibration of a measurement point is simulated which is favorably comparable to the measurement results.

Keywords Chatter · Indexable insert drill · Time-domain

\section{Introduction}

Vibrations usually reduce tool life, decrease the workpiece quality, and may cause damage to the machine [1,2]. Because of these negative effects, except cases such as vibration-assisted machining [3-5], vibrations are considered unwanted phenomena in machining processes. As mentioned by Tobias [1], vibrations in machining can be categorized into free, forced, and self-induced vibrations and all of these types of vibrations can have the mentioned negative effects. However, Tobias added, among mentioned types of vibrations, self-induced vibrations were more challenging because, at that time, the mechanisms of this type of vibrations were not completely known [1].

Since the scope of this paper is limited to self-induced vibrations, forced vibrations are not covered in this work. However, forced vibrations can have significant effects on the quality of metal cutting operations and if they are in lateral directions, they may cause significant surface marks on the wall of the hole. Interested readers may refer to [6-10] for more details on forced vibrations in metal cutting.

Self-induced vibrations have kept their important positions in metal cutting research for decades because of their complexity and negative effects on machining operations as pointed by Quintana et al. in a review paper on chatter in 2011 [11]. Different mechanisms can lead to self-induced vibrations in 
machining which can be categorized into two main types, namely primary and secondary $[11,12]$. The first type includes those generated by mechanisms in the cutting itself, such as tool-workpiece friction or mode coupling, and the second type is caused by a process known as regenerative chatter vibration $[11,12]$. In the process of regenerative chatter vibrations, a wavy surface is generated by motion of the tool relative to the workpiece due to a triggering dynamic force. In the next pass of the tool, this wavy surface modulates the current relative motion of the tool and workpiece and results in dynamic cutting forces which consequently affect the response of the structure [13].

Tobias and Fishwick [14] proposed a method to model regenerative chatter processes in drilling operations. Their focus was on machine tool deflections which affect the chip thickness. In general, any displacement in machine-toolworkpiece that affects the chip load might contribute to regenerative chatter vibrations. Over time, machine tools have become more rigid while an increase in stiffness of the drill bodies is restricted by geometric and economic considerations. Chatter can happen due to torsional, axial, and bending deflections of the drill body, and the mechanism of these chatter vibrations has been investigated in the past by several researchers. While the variation of the thrust force changes the length of the drill, torque variations also change the length of the drill due to helical geometry of chip flutes [15]. Changes in the length of the drill affect the chip thickness and thus the forces acting on the drill $[16,17]$. The resulted dynamic forces generate vibrations and can develop to form chatter vibrations.

Bayly et al. [16] have modeled torsional-axial chatter vibrations in drills. Considering orthogonality for the structural modes of the drill body and the fact that the dominant frequency in torsional-axial chatter vibration is very close to the first torsional mode, they assumed that the vibrational deflection of the drill is equal to deflection of the drill in its first torsional mode multiplied by a scaling factor. They obtained a delay differential equation with a constant delay while mentioning that the delay term varies slightly due to torsional vibrations [16]. Solving the mentioned delay differential equation determines if the process will be stable or not and hence the limit of radial depth of cut for chatter can be calculated. Arvajeh et al. in [18] combined this model with a bending chatter model proposed in [19] to model chattering both due to bending and torsional-axial vibrations. Roukema et al. [20] proposed a model for torsionalaxial vibration of twist drill which considers the effect of the torsional vibrations in the wave generation on the workpiece surface. While in the study done by Bayly et al. [16] that only the effect of the axial flexibility is included in the calculation of the chip thickness, the model proposed by Roukema et al. in [20] allows to consider the torsional flexibility in prediction of chip thickness in each time step. It is shown in [20] that when the torsional vibration is included in the model, the amplitude of the vibration reaches a lower limit. Later, Roukema et al. added the lateral deflections to the model proposed in [20] and developed a model to describe the vibration of the drill under torsional, axial, and bending modes $[21,22]$. While the proposed model in [21, 22] does not consider the effect of the process damping, a model is proposed by Ahmadi et al. in [23, 24] to include the process damping in the drilling stability and cutting force predictions. However, the chip thickness is calculated by considering a constant delay in the equations which affects the predictions of amplitudes of vibrations.

Considering that a variable delay strongly affects the amplitudes of vibrations and stability of the process [25], in this work, a time-domain approach is used that allows variation of the delay term due to the torsional vibrations. Although the method proposed in [20] considers the effect of torsional vibrations and hence it has a variable delay in the system, the main difference with the current paper is that the proposed method in the current paper is adapted for indexable drills by considering different dynamics for central and peripheral inserts. Another difference with the method proposed in [20] is that here, the workpiece surface is not simulated separately and this reduces the computation time considerably.

Due to torsional oscillations, there might be several time intervals in which the vibrational speed is larger than the rotational spindle speed; therefore, the drill rotates backwards. The proposed model in this work considers this effect and uses a simplistic way proposed in [25] to incorporate this phenomenon in the calculations. In the model presented in [25], a time-domain simulation is developed for drilling operations by considering the backward rotations of the cutting edge. In the current paper, that model is extended to include two inserts in the model. Including two inserts in the simulation is important because it allows designers to study the effects of changes in the design of inserts on the resulting dynamic behavior.

Indexable insert drills, shortened to indexable drills, which sometimes are called endrills [26], facilitate two or more indexable inserts as cutting edges to make holes. The positions of the inserts on the tool differ, which results in asymmetry of the geometry and the loading of the drill, and thus its dynamic behavior. The dynamics of asymmetric drills has not been investigated in previous research, and it will be addressed here. In addition, while the main stream in chatter vibration modeling is to predict chatter occurrence, this paper models the vibrational behavior when the drill is experiencing chatter vibrations. A time-domain approach is applied to include the effects of the variable delay, multiple previous cuts, interrupted cutting, and backward rotations of the tool which cause significant nonlinearities in the system. Although the type of drill considered in this work is 
an indexable insert drill with two inserts, the described method can be extended to drills with more inserts.

The rest of the paper is organized as follows: in Section 2, the mathematical model is explained in detail. Experimental setup is presented in Section 3, and the results of the simulation and measurements from experiment are presented and discussed in Sections 4 and 5 .

\section{Mathematical modeling}

In an indexable insert drill with two inserts, there is a central insert that cuts the center of the hole while the peripheral insert cuts the remaining part. Throughout the paper, superscripts $\mathrm{C}$ and $\mathrm{P}$ which represent central and peripheral inserts, respectively, are used to differentiate displacements, loadings, and chip loads of these two inserts.

As it is mentioned by Andrew et al. in [27], the changes of the cutting force due to structural displacements and the response of the system to these fluctuations in forces make a closed loop representing the system facing regenerative chatter. Based on this, the method proposed in this work consists of following main steps:

- To calculate the cutting torques and axial forces for given chip thickness of each insert

- To calculate displacements due to structural response to cutting forces and rigid body motions

- To calculate the chip thickness for each insert by comparing the current locations of inserts with their locations in previous cuts

A well-known approach to estimate cutting loads is a linear method which assumes a linear relationship between loads and the thickness of uncut chip [28]. Based on this assumption, Eqs. (1) and (2) are used to obtain torques $\left(T^{\mathrm{C}}, T^{\mathrm{P}}\right)$ and axial forces $\left(F_{z}^{\mathrm{C}}, F_{z}^{\mathrm{P}}\right)$ from chip thicknesses $\left(h^{\mathrm{C}}, h^{\mathrm{P}}\right)$.

$T^{i}=a_{T}^{i} \cdot h^{i}+b_{T}^{i}$.

$F_{z}^{i}=a_{F_{z}}^{i} \cdot h^{i}+b_{F_{z}}^{i}$.

In Eqs. (1) and (2), the superscript $i$ determines the insert which can be $\mathrm{C}$ or $\mathrm{P}$. The unit of chip thicknesses, $h^{i}$, is millimeter. The constant coefficients $\left(a_{T}^{i}\right.$, $\left.b_{T}^{i}, a_{F_{z}}^{i}, b_{F_{z}}^{i}\right)$ depend on the cutting edge geometries and workpiece-material and must be estimated to perform the chatter simulation.

In the simulation model, the amount of torques and axial forces generated by each insert is required separately. The total torque and axial force are the summations of generated torques and axial forces by central and peripheral inserts. To determine the contribution of each insert to the total loads, Eqs. (3)-(6) are used.

$F_{z}^{C}=\frac{l^{C}}{l^{C}+l^{P}} \cdot F_{z}^{\text {total }}$.

$F_{z}^{P}=F_{z}^{\text {total }}-F_{z}^{C}$.

$T^{C}=\left(\frac{l^{C}}{l^{C}+l^{P}}\right)^{2} \cdot T^{\text {total }}$

$T^{P}=T^{\text {total }}-T^{C}$.

$l^{C}$ and $l^{P}$ are widths of uncut chips of central and peripheral inserts respectively. After calculating the loads generated by each insert, linear regression is used to obtain the coefficients of Eqs. (1) and (2). In the presence of vibrations, chip thicknesses $\left(h^{i}\right)$ are time dependent scalar values and in a discrete representation, Eqs. (1) and (2) can be used to obtain torque and axial force at the $n$th time step as follows:

$$
\begin{aligned}
& T^{i}[n]=a_{T}^{i} \cdot h^{i}[n]+b_{T}^{i} . \\
& F_{z}^{i}[n]=a_{F_{z}}^{i} \cdot h^{i}[n]+b_{F_{z}}^{i} .
\end{aligned}
$$

Due to the axial force and the torque, cutting edges on the drill move and these motions affect the relative distance between the cutting edges and the workpiece and in turn the chip loads. Because of warping of the noncircular cross section of the drill and helical flutes, deflections are not the same at different points on the drill tip. Since the position of each insert on the tool affects its displacements, each insert needs its own degrees of freedom in the model. In this study, axial and angular motions of the inserts are considered. Therefore, for drills with two indexable inserts, the number of degrees of freedom in the simulation model becomes four, Table 1.

The axial and angular deflections are coupled in drills with helical flutes [17, 29], and these types of drills have a torsional-axial mode which includes axial and angular deflections simultaneously. Figure 1 shows the simultaneous angular and axial deflection of the drill when it is twisted or compressed.

The loading-displacement relationships between these four degrees of freedom are described using 16 frequency response functions, FRFs. FRFs can be estimated either analytically, experimentally, or numerically for example by finite element models. In this study, a global damping ratio, extracted from experiments is used in a finite element model to obtain the frequency response functions. The finite element approach was used to calculate the FRFs because high torsional 
Table 1 Degrees of freedom of the system

\begin{tabular}{lll}
\hline Degree of freedom & Insert & Direction \\
\hline 1 & Central & Axial \\
2 & Peripheral & Axial \\
3 & Central & Angular \\
4 & Peripheral & Angular \\
\hline
\end{tabular}

frequency affects the quality of FRF measurements. The list of the FRFs and their inputs and outputs are given in Table 2. In Table $2, \Delta \theta$ and $\Delta z$ represent angular and axial displacements, respectively. $H_{i j}$ is the frequency response function when $U_{i}$ is the output deflection and $F_{j}$ is the input excitation force and is calculated as a function of excitation frequency, $f$, as shown in the following equation [30]:

$H_{i j}(f)=\frac{U_{i}(f)}{F_{j}(f)}$.

As a result of the reciprocity principle, $H_{i j}$ is equal to $H_{j i}$ [30], which means that there are six identical pairs in these $16 \mathrm{FRFs}$; therefore, ten frequency response functions are required to be estimated. By obtaining mass, stiffness, and damping from frequency response function, equation of motions for the system is written as follows:

$$
\mathbf{M u ̈}+\mathbf{C} \dot{\mathbf{u}}+\mathbf{K u}=\mathbf{f} .
$$

Equation (10) is a system of 16 uncoupled differential equations. Here, $\mathbf{u}$ is the deflection vector as shown in Eq. (11) and $\dot{\boldsymbol{u}}$ and $\ddot{\boldsymbol{u}}$ are its time derivatives. $\mathbf{f}$ is the load vector as shown in Eq. (12). M, C, and $\mathbf{K}$ are $16 \times 16$ diagonal matrices and the diagonals of these matrices

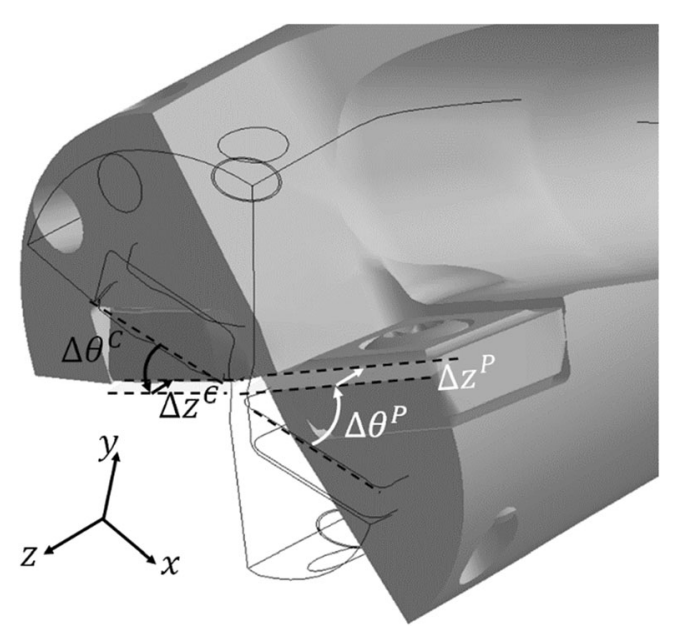

Fig. 1 Angular and axial deflections ( $\Delta \theta$ and $\Delta z$ ) of the drill
Table 2 The list of frequency response functions

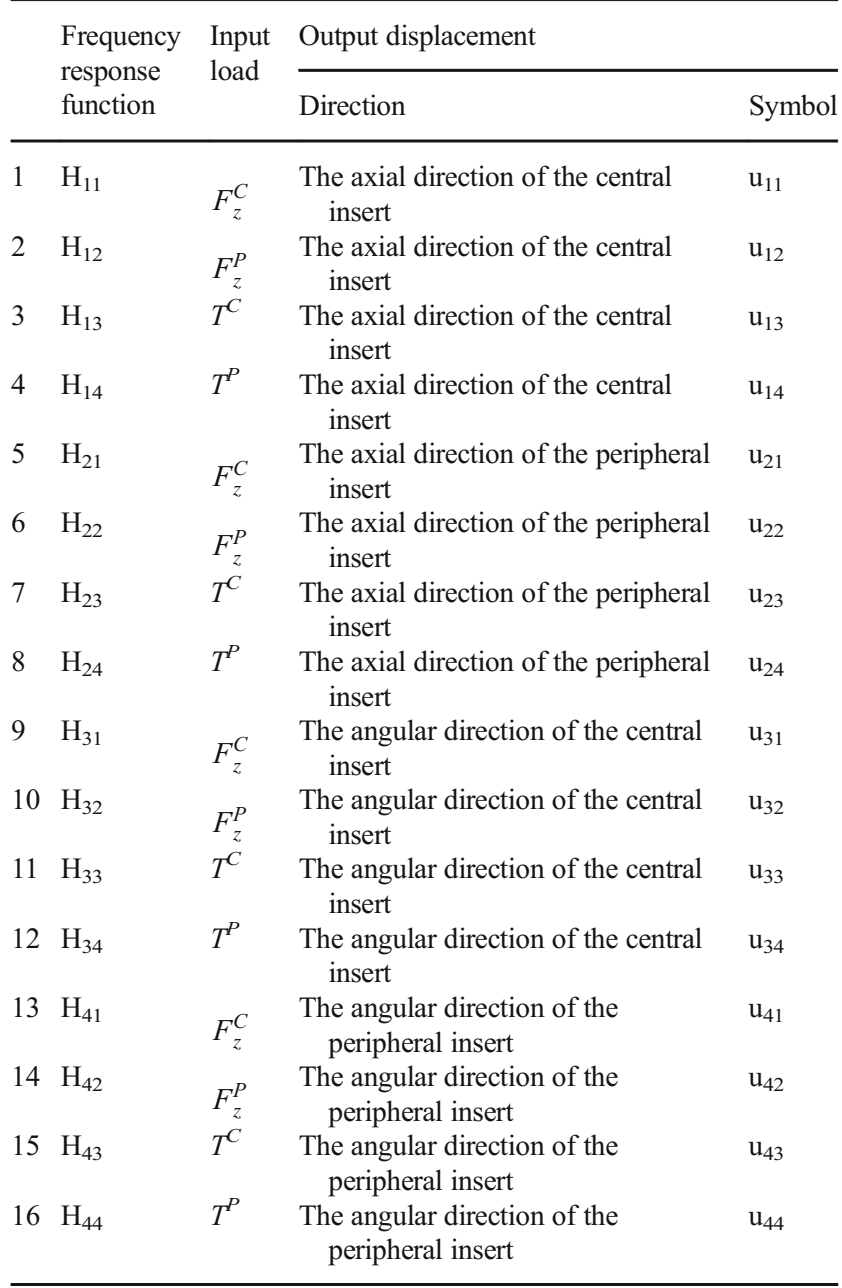

are filled with mass, damping, and stiffness values obtained from FRFs.

$\mathbf{u}=\left[\begin{array}{llllllllllllllll}u_{11} & u_{12} & u_{13} & u_{14} & u_{21} & u_{22} & u_{23} & u_{24} & u_{31} & u_{32} & u_{33} & u_{34} & u_{41} & u_{42} & u_{43} & u_{44}\end{array}\right]^{T}$.

$\mathbf{f}=\left[\begin{array}{llllllllllllllll}F_{z}^{C} & F_{z}^{P} & T^{C} & T^{P} & F_{z}^{C} & F_{z}^{P} & T^{C} & T^{P} & F_{z}^{C} & F_{z}^{P} & T^{C} & T^{P} & F_{z}^{C} & F_{z}^{P} & T^{C} & T^{P}\end{array}\right]^{T}$.

The vibrational displacements of each insert at each direction are calculated as follows:

$$
\begin{aligned}
\Delta z^{C} & =\sum_{j=1}^{4} u_{1 j} \\
\Delta z^{P} & =\sum_{j=1}^{4} u_{2 j} \\
\Delta \theta^{C} & =\sum_{j=1}^{4} u_{3 j} \\
\Delta \theta^{P} & =\sum_{j=1}^{4} u_{4 j}
\end{aligned} .
$$

$\Delta z^{i}$ and $\Delta \theta^{i}$ represent the axial and the angular vibrations, respectively. In this work, the fourth-order Runge- 
Kutta method is used to solve the system of differential equation shown in Eq. (10). To follow the Runge-Kutta scheme, a vector variable, $\mathbf{y}$, is introduced as shown in Eq. (14):

$$
\begin{aligned}
& \mathbf{y}=\left\{\begin{array}{c}
\mathbf{u} \\
\dot{\mathbf{u}}
\end{array}\right\} \\
& \dot{\mathbf{y}}=\left\{\begin{array}{c}
\dot{\mathbf{u}} \\
\ddot{\mathbf{u}}
\end{array}\right\} .
\end{aligned}
$$

In Eq. (14), dots represent time derivatives. $\ddot{u}$ is calculated by rewriting Eq. (10) as follows:

$$
\ddot{\mathbf{u}}=\mathbf{M}^{-1}(\mathbf{f}-\mathbf{C} \dot{\mathbf{u}}-\mathbf{K u}) \text {. }
$$

Considering Eqs. (14) and (15), $\dot{\mathbf{y}}$ can be written as a function of time $(t)$ and $\mathbf{y}$ :

$\dot{\mathbf{y}}=\mathbf{g}(t, \mathbf{y})$.

The system of differential equations presented in Eq. (16) is solved by assuming $\mathbf{y}=\mathbf{0}$ at the beginning. During the drilling operation, the drill rotates and moves in axial direction relative to the workpiece. Angular and axial rigid body motions at each time step ( $\Delta \theta^{\text {rigid }}$ and $\Delta z^{\text {rigid }}$, respectively) are obtained as shown in Eq. (17).

$\Delta \theta^{\text {rigid }}=\Omega \cdot \Delta t$

$\Delta z^{\text {rigid }}=\frac{f_{n}}{2000 \pi} \cdot \Delta \theta^{\text {rigid }}$.

In Eq. (17), $\Delta t$ is the time step in seconds, $\Omega$ is the tool angular speed in radians per second, and $f_{n}$ is the axial feed in millimeters per revolution. The time step was chosen in a way that $1 / \Delta t$ is about 21 times as large as the torsional resonance frequency. In each time step, deflections are obtained from solving Eq. (16) and are then used to calculate axial and angular positions of the inserts, $\mathbf{q}$, at the $n$th time step as follows:

$$
\mathbf{q}[n]=\left\{\begin{array}{c}
z^{C} \\
z^{P} \\
\theta^{C} \\
\theta^{P}
\end{array}\right\}=\left\{\begin{array}{c}
n \Delta z^{\text {rigid }}+\sum_{j=1}^{4} u_{1 j} \\
n \Delta z^{\text {rigid }}+\sum_{j=1}^{4} u_{2 j} \\
n \Delta \theta^{\text {rigid }}+\sum_{j=1}^{4} u_{3 j} \\
n \Delta \theta^{\text {rigid }}+\sum_{j=1}^{4} u_{4 j}
\end{array}\right\} .
$$

As shown in Eq. (19), to estimate the chip thickness, $h^{i}[n]$, the current position of the cutting edge, $z^{i}[n]$, is compared to the positions of the insert at previous tool passes, where angular position of the insert was equal to $\theta^{i}[n]-2 k \pi$. $h^{i}[n]=z^{i}[n]-\max \left(\left.z^{i}\right|_{\theta^{i}=\theta^{i}[n]-2 k \pi}\right), \quad k=0,1,2, \ldots$.

By changes in $k$, more than one delay is considered in the model. This is an approach to involve more than one preceding cuts and it has been used by Tlusty and Ismail in modeling of milling [31]. When the amplitudes of vibrations are large, the cutting edge might jump out of cut. This phenomenon which has been mentioned in, e.g., [31] affects the dynamic of the system and therefore needs to be considered in the model. If the calculated chip thickness is a negative value, this shows that the cutting edge is not engaged in the workpiece and therefore cutting loads are zero. Additionally, in some time intervals, the torsional vibrations are so large that they cause the drill to move backwards [21, $25]$, i.e., the edge has a negative velocity relative to the workpiece $\left(\Delta \dot{\theta}^{i}+\Omega<0\right)$. In such cases, the tool touches the workpiece by the flank face if $h^{i}[n]>0$.

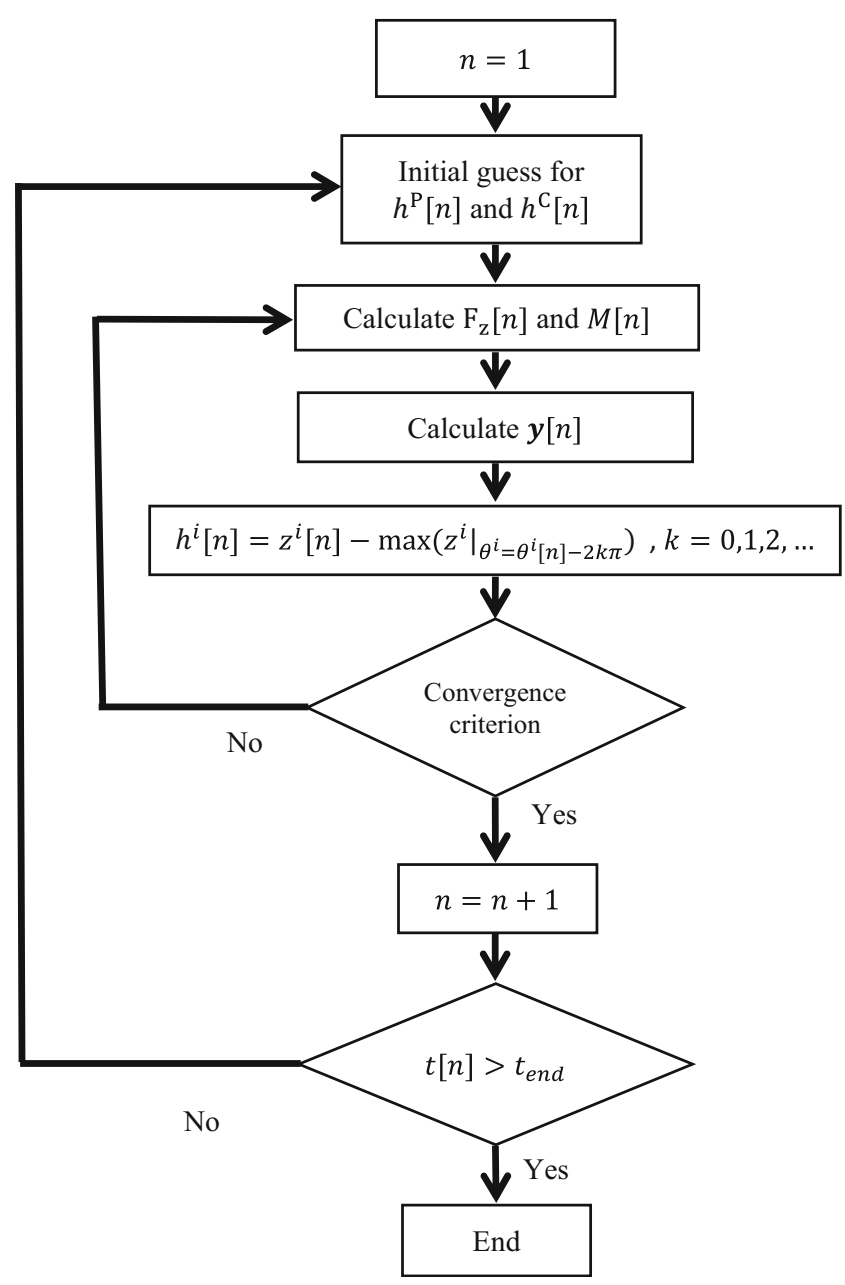

Fig. 2 The flow chart of the simulation routine 
Table 3 Specifications of the tool

\begin{tabular}{ll}
\hline Diameter & $24 \mathrm{~mm}$ \\
Length & $96 \mathrm{~mm}$ \\
Product code & $880-$ D2400L25-04 \\
\hline
\end{tabular}

Since the rake face is not cutting, Eqs. (7) and (8) cannot be used. In the model proposed in [21], it is assumed that no chip removal takes place in these situations, while in this work, it is assumed that the surface is deformed by rubbing the flank face over the workpiece. Only edge coefficients $\left(b_{T}^{i}, b_{F_{2}}^{i}\right)$ are used to calculate cutting forces [25], which means constant friction forces are applied. The Coulomb friction assumption to describe the interaction between the flank face and surface of the workpiece in the case of backward motions has been used by Wiercigroch [32]. Equations (20) and (21) show how cutting loads are calculated depending on the direction of motions of cutting edge relative to the workpiece:

$$
\begin{aligned}
& T^{i}[n]=\left\{\begin{array}{ll}
a_{T}^{i} \cdot h^{i}[n]+b_{T}^{i} & h^{i}[n]>0 \text { and } \Delta \dot{\theta}^{i}[n]+\Omega \geq 0 \\
-b_{T}^{i} & h^{i}[n]>0 \text { and } \Delta \dot{\theta}^{i}[n]+\Omega<0 \\
0 & h^{i}[n] \leq 0
\end{array} .\right. \\
& F_{z}^{i}[n]= \begin{cases}a_{F_{z}}^{i} \cdot h^{i}[n]+b_{F_{z}}^{i} & h^{i}[n]>0 \text { and } \Delta \dot{\theta}^{i}[n]+\Omega \geq 0 \\
b_{F_{z}}^{i} & h^{i}[n]>0 \text { and } \Delta \dot{\theta}^{i}[n]+\Omega<0 . \\
0 & h^{i}[n] \leq 0\end{cases}
\end{aligned}
$$

The axial forces and torques generated by both inserts are summed up to obtain the total torque, $T[n]$, and axial force, $F_{z}[n]$, at each time step:

$$
\begin{aligned}
& T[n]=T^{P}[n]+T^{C}[n] . \\
& F_{z}[n]=F_{z}^{P}[n]+F_{z}^{C}[n] .
\end{aligned}
$$

The force vector, $\mathbf{f}$, is required at each time step to solve Eq. (10) and obtain the current positions of the cutting edges. However, at the same time, the force vector depends on the current positions of the edges.
An iterative approach is applied to handle this nonlinearity. The calculated forces are used in Eqs. (14)-(18) to calculate the positions of the edges at the current time step. The obtained positions are used in Eq. (19) to calculate the chip thicknesses. The current chip thicknesses are then updated and the iterations continue until the fulfillment of the convergence criterion. The convergence criterion is that differences in angular positions of both inserts in two successive iterations should be smaller than a predefined error. Figure 2 shows a flow chart of the suggested algorithm.

By using the simulated forces, it is possible to predict dynamic displacements of any arbitrary point on the drill body. The simulated forces are used to predict the tangential vibrations of a measurement point as described in the next sections. In this paper, tangential direction refers to the direction that is perpendicular to the drill axis and tangent to the circumscribing cylinder of the drill at the measurement point.

\section{Experimental setup}

An indexable drill from Sandvik Coromant, with two inserts and specifications shown in Table 3, was used in the drilling test. The measurement was conducted in a turning machine; therefore, the workpiece was rotating while the drill was moving in axial direction to provide the axial feed.

The cutting process was performed without applying coolant to avoid damaging lasers and electronic parts of the setup. A laser was used to measure the speed at a point on the drill (D) as shown in Figs. 3 and 4 at a sampling frequency of $83,333 \mathrm{~Hz}$. The setup is shown in Figs. 4 and 5. The measurement point (D) was located at a distance of $210 \mathrm{~mm}$ from the laser and $48 \mathrm{~mm}$ from the top of the drill.

The tangential speed at the measurement point is not at the direction of the laser beam (the red line). This means the angle between the laser beam and the radial direction at the
Fig. 3 Measurement point D at the edge of the central flute and in a distance of $48 \mathrm{~mm}$ from the top of the drill

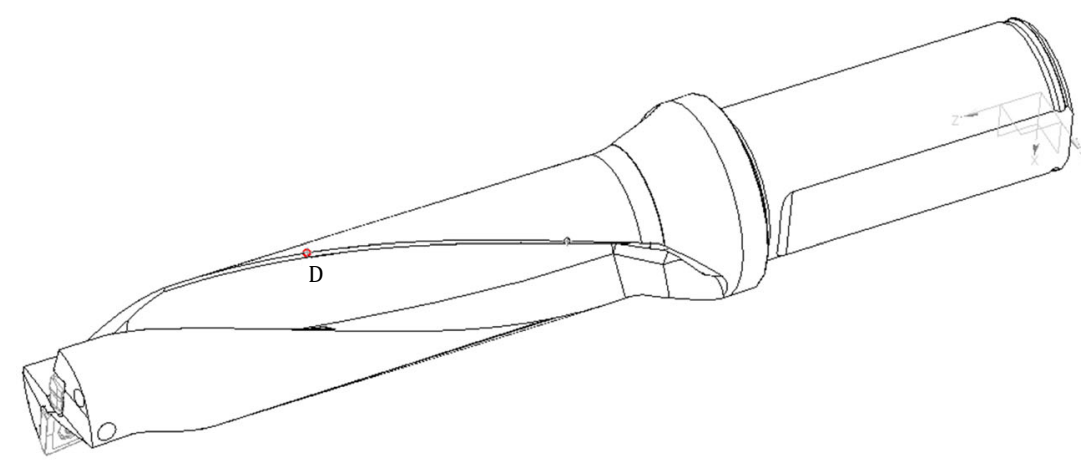




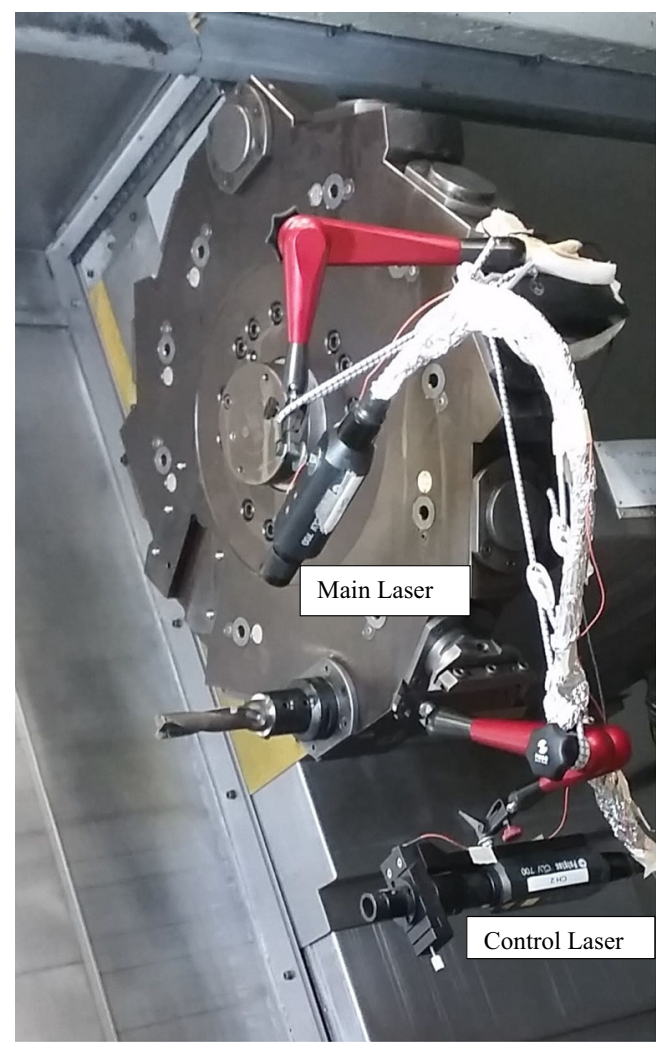

Fig. 4 Experimental setup for measuring tangential speed

measurement point (the green line) is not $90^{\circ}$. This angle is called $\theta$, as shown in Fig. 6, and it can be calculated as given in Eq. (24). $\theta=\operatorname{acos}\left(\frac{\mathbf{v}_{1} \cdot \mathbf{v}_{2}}{\left|\mathbf{v}_{1}\right|\left|\mathbf{v}_{2}\right|}\right)=143.4 \operatorname{deg}$.

The measured speed is divided by $\cos (\theta)$ to get the tangential speed at the measurement point.

\section{Comparison between simulation and experimental results}

The same drill as described in the previous section is used in the simulation. The Young's modulus of $210 \mathrm{GPa}$, Poisson's ratio of 0.3 , and density of $7800 \mathrm{~kg} / \mathrm{m}^{3}$ are used for the tool material. The damping ratio for the tool body is extracted from the experiment as $\zeta=0.16 \%$, and it is used in a finite element model to calculate the required frequency response functions. Mass, stiffness, and damping, extracted from the obtained frequency response functions, are presented in Table 4.

In some of the frequency response functions, shown in Table 4, values are negative due to the fact that in these FRFs, static load and deformations are in opposite directions. For example, in $\mathrm{H}_{13}$, while static torque increases, the drill shortens and central insert moves in negative direction of $z$-axis.

The workpiece material is $34 \mathrm{CrNiMoS6}$ (SS 2541) and since no coolant is used in vibration measurements, the cutting force measurement has been conducted
Fig. 5 Location of the laser. The red line connects the laser to the measurement point $\mathrm{D}$. The green line connects the center of the drill to $\mathrm{D}$ and the blue line connects the center of the drill to the laser

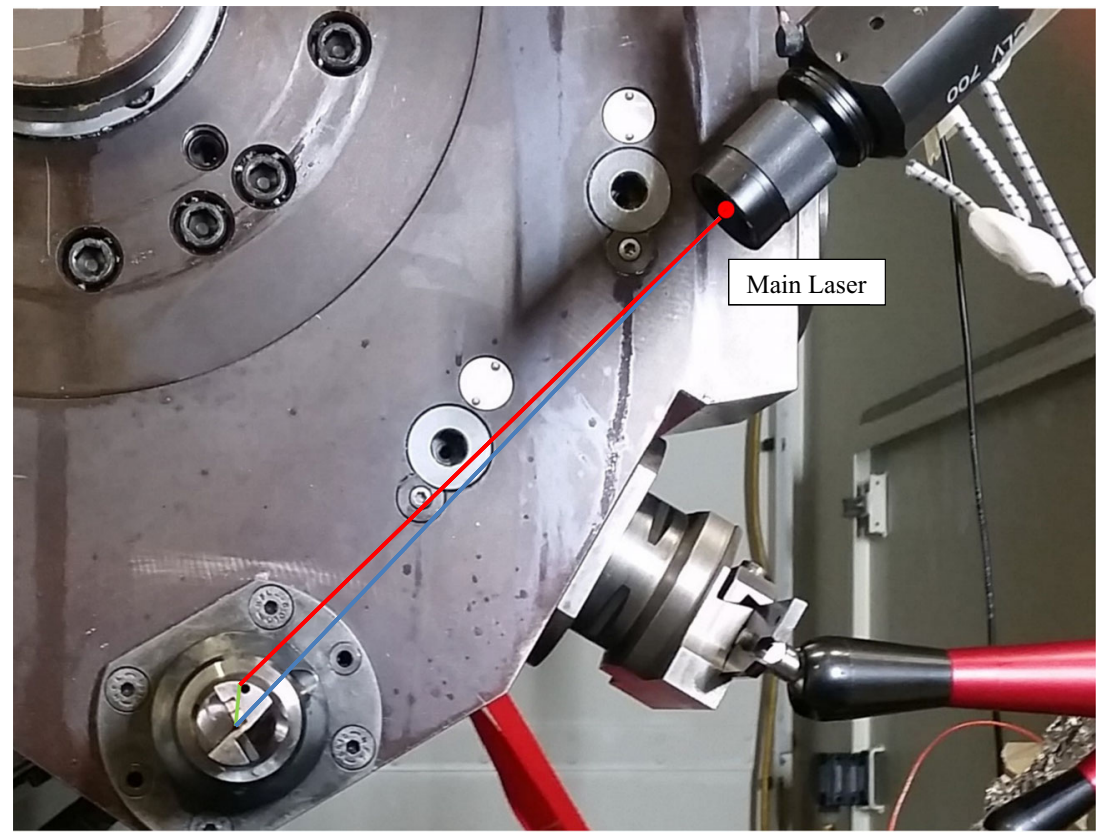




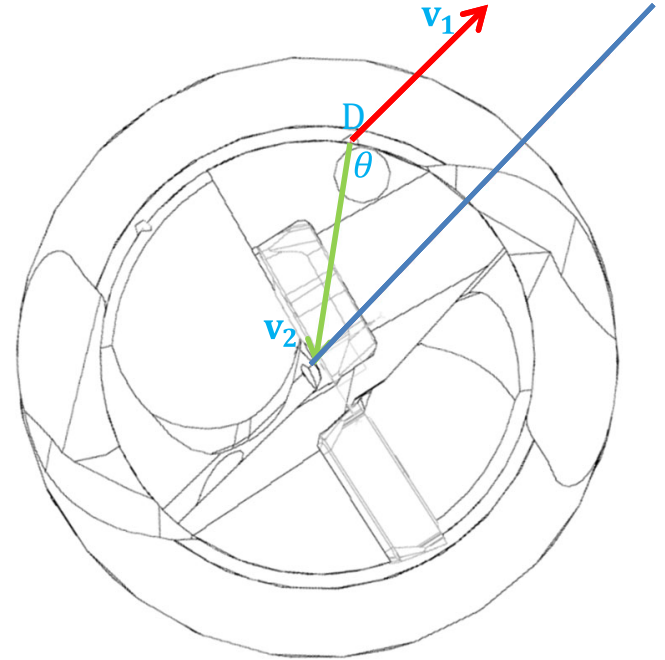

Fig. 6 Angle, $\theta$, between the laser beam (the red vector, $\mathbf{v}_{1}$ ) and the radial direction on the measurement point (the green vector, $\mathbf{v}_{\mathbf{2}}$ )

without applying coolant too. The average values of axial forces and torques at different feed rates at the cutting speed of $200 \mathrm{~m} / \mathrm{min}$ are calculated from the measurement data and are shown in Table 5.

Torques and axial forces are negative values because of orientation of coordinate system as shown in Fig. 1 .
The width of the uncut chip of the central insert, $l^{C}$, and the peripheral insert, $l^{P}$, is 6.19 and $5.81 \mathrm{~mm}$, respectively. Generated torques and axial forces are estimated using Eq. (3)-(6) and are shown in Table 6.

The linear regressions for the values in Table 6 are as follows:

$T^{C}=-29.5 h-2.3$

$T^{P}=-81.4 h-6.4$

$F_{z}^{C}=-2178 h-1279$

$F_{z}^{P}=-2040 h-1201$

Drilling is simulated using the mathematical model described in the previous section, and iterations are conducted in each time step until the differences in angular positions of the inserts in two successive iterations are less than $8 \times 10^{-4} \mathrm{rad}$.

While the simulation estimates speeds at the top of the drill, the experimental setup measures speeds at point $\mathrm{D}$, as shown in Fig. 3, which is more convenient for the measurement. Since the top of the drill goes into the hole during the cutting process, it is not possible to use the proposed setup to measure its speed. Therefore, point $\mathrm{D}$ is used to compare the simulated and the experimental results.

Table 4 Dynamic parameters

\begin{tabular}{|c|c|c|c|c|c|c|}
\hline & FRF & Load & Displacement & Mass & Damping & Stiffness \\
\hline 1 & $\mathrm{H}_{11}$ & $F_{z}^{C}$ & $z^{C}$ & $1.72 \mathrm{~kg}$ & $1.53 \times 10^{2} \mathrm{~kg} / \mathrm{s}$ & $1.14 \times 10^{9} \mathrm{~N} / \mathrm{m}$ \\
\hline 2 & $\mathrm{H}_{12}$ & $F_{z}^{P}$ & $z^{C}$ & $1.68 \mathrm{~kg}$ & $1.49 \times 10^{2} \mathrm{~kg} / \mathrm{s}$ & $1.11 \times 10^{9} \mathrm{~N} / \mathrm{m}$ \\
\hline 3 & $\mathrm{H}_{13}$ & $T^{C}$ & $z^{C}$ & $-3.21 \times 10^{-3} \mathrm{kgm}$ & $-2.64 \times 10^{-1} \mathrm{kgm} / \mathrm{s}$ & $-2.12 \times 10^{6} \mathrm{Nm} / \mathrm{m}$ \\
\hline 4 & $\mathrm{H}_{14}$ & $T^{P}$ & $z^{C}$ & $-3.09 \times 10^{-3} \mathrm{kgm}$ & $-2.54 \times 10^{-1} \mathrm{kgm} / \mathrm{s}$ & $-2.04 \times 10^{6} \mathrm{Nm} / \mathrm{m}$ \\
\hline 5 & $\mathrm{H}_{21}$ & $F_{z}^{C}$ & $z^{P}$ & $1.68 \mathrm{~kg}$ & $1.49 \times 10^{2} \mathrm{~kg} / \mathrm{s}$ & $1.11 \times 10^{9} \mathrm{~N} / \mathrm{m}$ \\
\hline 6 & $\mathrm{H}_{22}$ & $F_{z}^{P}$ & $z^{P}$ & $1.77 \mathrm{~kg}$ & $1.44 \times 10^{2} \mathrm{~kg} / \mathrm{s}$ & $1.17 \times 10^{9} \mathrm{~N} / \mathrm{m}$ \\
\hline 7 & $\mathrm{H}_{23}$ & $T^{\tilde{C}}$ & $z^{P}$ & $-3.12 \times 10^{-3} \mathrm{kgm}$ & $-2.58 \times 10^{-1} \mathrm{kgm} / \mathrm{s}$ & $-2.06 \times 10^{6} \mathrm{Nm} / \mathrm{m}$ \\
\hline 8 & $\mathrm{H}_{24}$ & $T^{P}$ & $z^{P}$ & $-3.00 \times 10^{-3} \mathrm{kgm}$ & $-2.48 \times 10^{-1} \mathrm{kgm} / \mathrm{s}$ & $-1.98 \times 10^{6} \mathrm{Nm} / \mathrm{m}$ \\
\hline 9 & $\mathrm{H}_{31}$ & $F_{z}^{C}$ & $\theta^{C}$ & $-3.21 \times 10^{-3} \mathrm{kgm} / \mathrm{rad}$ & $-2.64 \times 10^{-1} \mathrm{Ns} / \mathrm{rad}$ & $-2.12 \times 10^{6} \mathrm{~N} / \mathrm{rad}$ \\
\hline 10 & $\mathrm{H}_{32}$ & $F_{z}^{P}$ & $\theta^{C}$ & $-3.10 \times 10^{-3} \mathrm{kgm} / \mathrm{rad}$ & $-2.57 \times 10^{-1} \mathrm{Ns} / \mathrm{rad}$ & $-2.05 \times 10^{6} \mathrm{~N} / \mathrm{rad}$ \\
\hline 11 & $\mathrm{H}_{33}$ & $T^{c}$ & $\theta^{C}$ & $5.55 \times 10^{-6} \mathrm{kgm}^{2} / \mathrm{rad}$ & $4.57 \times 10^{-4} \mathrm{Nms} / \mathrm{rad}$ & $3.67 \times 10^{3} \mathrm{Nm} / \mathrm{rad}$ \\
\hline 12 & $\mathrm{H}_{34}$ & $T^{P}$ & $\theta^{C}$ & $5.34 \times 10^{-6} \mathrm{kgm}^{2} / \mathrm{rad}$ & $4.39 \times 10^{-4} \mathrm{Nms} / \mathrm{rad}$ & $3.53 \times 10^{3} \mathrm{Nm} / \mathrm{rad}$ \\
\hline 13 & $\mathrm{H}_{41}$ & $F_{z}^{C}$ & $\theta^{P}$ & $-3.09 \times 10^{-3} \mathrm{kgm} / \mathrm{rad}$ & $-2.54 \times 10^{-1} \mathrm{Ns} / \mathrm{rad}$ & $-2.04 \times 10^{6} \mathrm{~N} / \mathrm{rad}$ \\
\hline 14 & $\mathrm{H}_{42}$ & $F_{z}^{P}$ & $\theta^{P}$ & $-3.00 \times 10^{-3} \mathrm{kgm} / \mathrm{rad}$ & $-2.48 \times 10^{-1} \mathrm{Ns} / \mathrm{rad}$ & $-1.98 \times 10^{6} \mathrm{~N} / \mathrm{rad}$ \\
\hline 15 & $\mathrm{H}_{43}$ & $T^{C}$ & $\theta^{P}$ & $5.34 \times 10^{-6} \mathrm{kgm}^{2} / \mathrm{rad}$ & $4.39 \times 10^{-4} \mathrm{Nms} / \mathrm{rad}$ & $3.53 \times 10^{3} \mathrm{Nm} / \mathrm{rad}$ \\
\hline 16 & $\mathrm{H}_{44}$ & $T^{P}$ & $\theta^{P}$ & $5.14 \times 10^{-6} \mathrm{kgm}^{2} / \mathrm{rad}$ & $4.23 \times 10^{-4} \mathrm{Nms} / \mathrm{rad}$ & $3.40 \times 10^{3} \mathrm{Nm} / \mathrm{rad}$ \\
\hline
\end{tabular}


Table 5 Average axial forces and torques at cutting speed of $200 \mathrm{~m} / \mathrm{min}$ and different feeds

\begin{tabular}{llll}
\hline Feed $(\mathrm{mm} / \mathrm{rev})$ & $\begin{array}{l}\text { Cutting speed } \\
(\mathrm{m} / \mathrm{min})\end{array}$ & Torque $(\mathrm{N} / \mathrm{m})$ & Axial force $(\mathrm{N})$ \\
\hline 0.12 & 200 & -21.94 & -2955 \\
0.14 & 200 & -24.35 & -3119 \\
0.18 & 200 & -28.63 & -3224 \\
\hline
\end{tabular}

Table 6 Estimated torques and axial forces generated by central and peripheral insert

\begin{tabular}{|c|c|c|c|c|c|}
\hline \multirow{2}{*}{$\begin{array}{l}\text { Feed } \\
(\mathrm{mm} / \\
\text { rev })\end{array}$} & \multirow{2}{*}{$\begin{array}{l}\text { Cutting } \\
\text { speed } \\
(\mathrm{m} / \mathrm{min})\end{array}$} & \multicolumn{2}{|c|}{ Torque (Nm) } & \multicolumn{2}{|c|}{ Axial force $(\mathrm{N})$} \\
\hline & & $\begin{array}{l}\text { Peripheral } \\
\text { insert }\end{array}$ & $\begin{array}{l}\text { Central } \\
\text { insert }\end{array}$ & $\begin{array}{l}\text { Peripheral } \\
\text { insert }\end{array}$ & $\begin{array}{l}\text { Central } \\
\text { insert }\end{array}$ \\
\hline 0.12 & 200 & -16.10 & -5.84 & -1431 & -1524 \\
\hline 0.14 & 200 & -17.87 & -6.48 & -1510 & -1609 \\
\hline 0.18 & 200 & -21.01 & -7.62 & -1561 & -1663 \\
\hline
\end{tabular}

To simulate the vibrations of the measurement point, $\mathrm{D}$, simulated dynamic axial forces and torques are applied on the drill and angular displacement of the point $\mathrm{D}$ is estimated by summing up the angular displacements generated by torques and axial forces of central and peripheral inserts as shown in Eq. (29).

$\theta^{D}=H_{51} \cdot F_{z}^{C}+H_{52} \cdot F_{z}^{P}+H_{53} \cdot T^{C}+H_{54} \cdot T^{P}$

$H_{51}-H_{54}$ are frequency response functions between the top of the drill and the angular motion of the measurement point, $\mathrm{D}$, as given in Table 7. The finite element approach is used to obtain these frequency response functions.

The obtained angular speed is multiplied by the radius of the drill $(r=12 \mathrm{~mm})$ to obtain tangential speed of the drill at the point $\mathrm{D}$.

The measured and simulated tangential speeds of a drilling process when the cutting speed and the feed rate are $200 \mathrm{~m} /$ min and $0.1 \mathrm{~mm} / \mathrm{rev}$, respectively, are shown in Fig. 7 and the spectra of these signals are shown in Fig. 8.
As shown in Fig. 7, the amplitude of the simulated vibration is around $80 \%$ of the experimental one. In the frequency domain, the model predicts the frequency of the chatter around $143 \mathrm{~Hz}$ above the experimental value which is around $4 \%$ error. Considering Figs. 7 and 8 , the model shows a reasonable agreement with the measurements.

Torsional vibrations may cause backward rotations [20]. As mentioned in Section 2, Eqs. (20) and (21) are used to calculate forces in such cases. The effects of this phenomenon on torque and axial forces appear in the form of spikes in simulation results as shown in Figs. 9 and 10.

As it can be seen in Figs. 9 and 10, the generated dynamic torques and axial forces have different patterns for central and peripheral inserts. In this case, the peripheral insert is generally experiencing more backward cuttings which are represented by more spikes in the simulation results for the torque and the axial force as shown in Figs. 9 and 10. Another point is that the dynamic part of the torque is around $28 \%$ of its static part which is relatively high. Therefore, the effects of this high frequency, high amplitude dynamic changes need to be considered in the design of the drill. This dynamic variation is around $8 \%$ in the axial forces which is lower than variations in the torques but it is still significant.

Variations of torque and axial force generated by each insert cause torsional and axial vibrations of inserts as shown in Figs. 11 and 12. The total axial or torsional vibrations of each insert are achieved by the summing up of vibrations generated by all loads.

Contributions of forces to induced vibrations are not equal as shown in Figs. 11 and 12. Vibrations generated by torque variations are in opposite phase of vibration induced by axial variations. This could be explained considering the effect of helix angle of the flutes. Due to this, the axial force counters a part of displacements generated by torque and therefore plays a stabilizing role. Another observation is that, the effects of dynamic torques are considerably stronger

Table 7 Dynamic parameters for the angular deflection of the point $\mathrm{D}$

\begin{tabular}{|c|c|c|c|c|c|}
\hline & FRF & Load & Mass & Damping & Stiffness \\
\hline 1 & $\mathrm{H}_{51}$ & $F_{z}^{C}$ & $4.8 \times 10^{-3} \mathrm{kgm} / \mathrm{rad}$ & $4.04 \times 10^{-1} \mathrm{Ns} / \mathrm{rad}$ & $3.31 \times 10^{6} \mathrm{~N} / \mathrm{rad}$ \\
\hline 2 & $\mathrm{H}_{52}$ & $F_{z}^{P}$ & $3.8 \times 10^{-3} \mathrm{kgm} / \mathrm{rad}$ & $3.17 \times 10^{-1} \mathrm{Ns} / \mathrm{rad}$ & $2.60 \times 10^{6} \mathrm{~N} / \mathrm{rad}$ \\
\hline 3 & $\mathrm{H}_{53}$ & $T^{C}$ & $-4.72 \times 10^{-6} \mathrm{kgm}^{2} / \mathrm{rad}$ & $-3.97 \times 10^{-4} \mathrm{Nms} / \mathrm{rad}$ & $-3.25 \times 10^{3} \mathrm{Nm} / \mathrm{rad}$ \\
\hline 4 & $\mathrm{H}_{54}$ & $T^{P}$ & $-4.86 \times 10^{-6} \mathrm{kgm}^{2} / \mathrm{rad}$ & $-4.08 \times 10^{-4} \mathrm{Nms} / \mathrm{rad}$ & $-3.34 \times 10^{3} \mathrm{Nm} / \mathrm{rad}$ \\
\hline
\end{tabular}




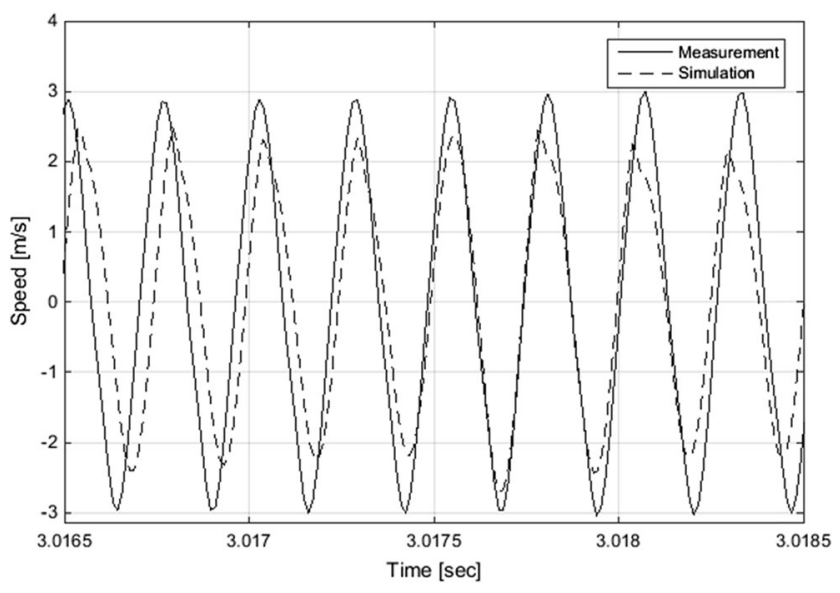

Fig. 7 The measured (solid line) and the simulated (dashed line) tangential speed at point $\mathrm{D}$

than the effects of dynamic axial forces in the simulated drilling.

The cutting speed of $200 \mathrm{~m} / \mathrm{min}$ and the tool diameter of $24 \mathrm{~mm}$ correspond to a spindle frequency of $44.2 \mathrm{~Hz}$. Considering the third natural frequency of the structure which is $4091 \mathrm{~Hz}$, there are around 92 vibrational cycles in each tool revolution. This means that each vibration cycle covers about $0.068 \mathrm{rad}$ of tool revolution. Comparing this value to torsional vibrations presented in Fig. 12 shows that vibrations can change the angular position of the inserts about $20 \%$ of a vibration cycle. This affects the delay time between two successive cuts as shown in Fig. 13.

If there are no torsional vibrations, the time interval between two successive cuts remains constant which can be represented as a constant delay. This constant
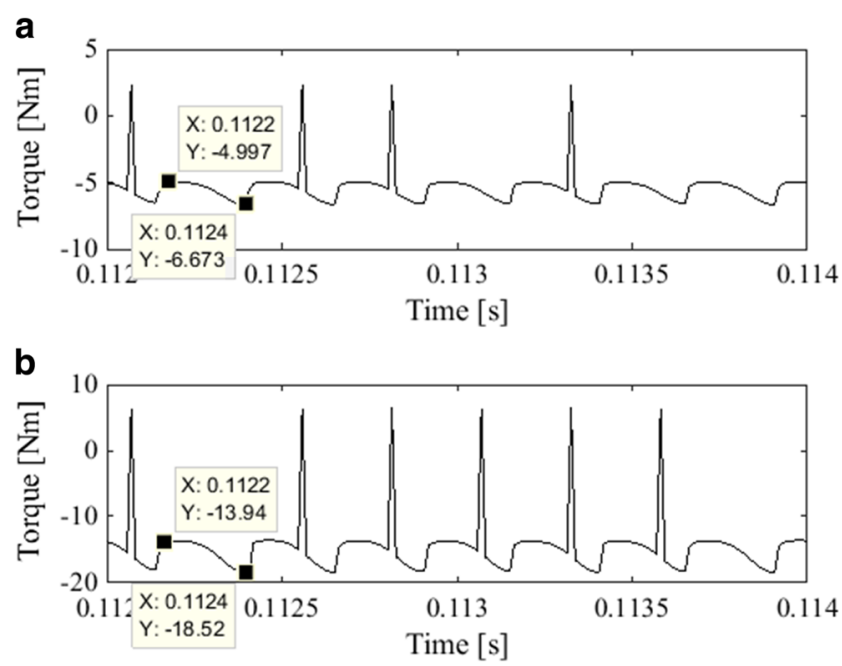

Fig. 9 Generated torques by central insert (a) and peripheral insert (b)

delay is equal to the required time for one complete rotation of spindle which is around $22.62 \mathrm{~ms}$ in the current simulation. However, due to torsional vibrations, the delay between two successive cuts is not constant and changes by time; this is shown in Fig. 13 for central insert.

If the torsional vibration is ignored in the model, the differential equations corresponding to frequency response functions 9-16 disappear from system dynamics and Eq. (16) is reduced to a system of eight differential equations. In this case, the time delay remains constant which affects the simulation results as shown in Fig. 14.

The simulated tangential speed at point $\mathrm{D}$ in the case of the variable delay and constant delay is compared to the measurement results in Fig. 14. As can be seen in Fig. 14, in the constant delay system (c), the

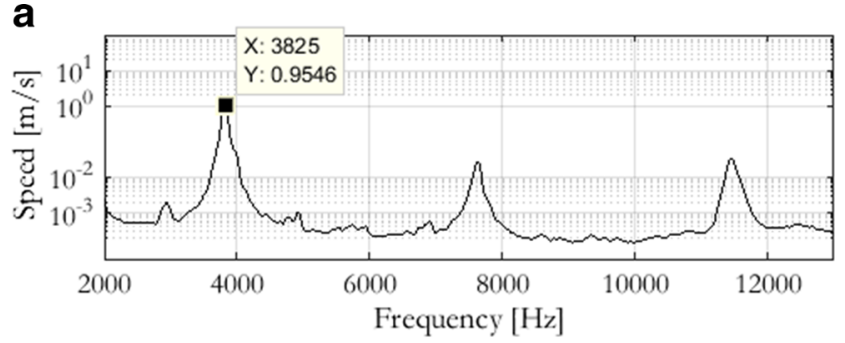

b

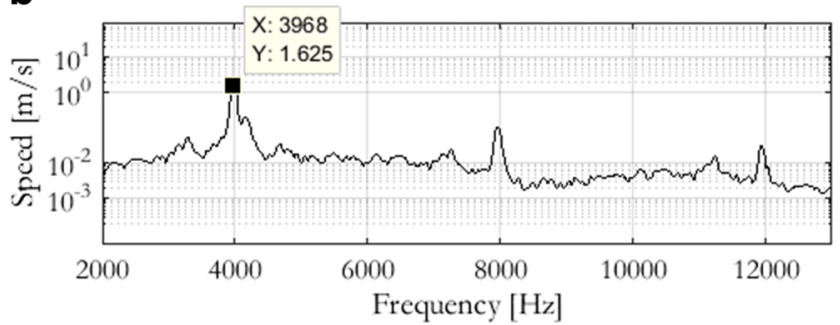

Fig. 8 a The spectrum of the measured tangential speed at point D. b The spectrum of the simulated tangential speed at point $\mathrm{D}$
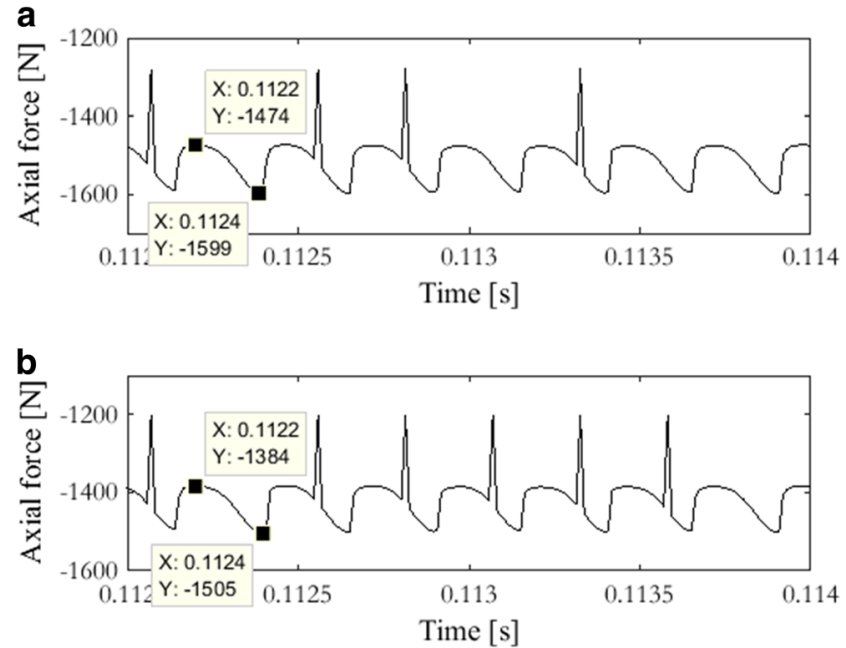

Fig. 10 Generated axial forces by central insert (a) and peripheral insert (b) 
Fig. 11 The axial vibration of the central insert (a) and the peripheral insert (b) due to axial forces and torques generated by the central and the peripheral inserts

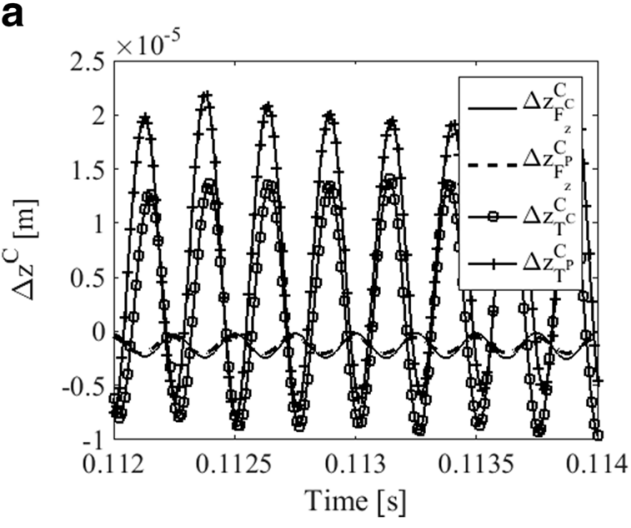

amplitude of the speed increases towards infinity, while it is limited in the case that considers the time delay variations $(b)$.

The dependence of the delay term on the state of the system and its varying nature, in combination with nonlinearities which arise from Eqs. (20) and (21), prevents the simulation of dynamics of drilling with analytical methods presented in the literature; however, using the presented time domain simulation, it was possible to overcome these difficulties.

\section{Conclusions}

A detailed model is proposed to simulate vibrations of indexable insert drills where regenerative chatter vibrations exist in axial and angular directions. This model enables a detailed study of the forces, torques, and movements. The importance of modeling of chatter rather than just predicting its occurrence comes from the fact that in many drilling operations, particularly with long drills, chatter exists due to large chip width; thus, it is more practical to reduce the amplitude of chatter vibrations by improving the design of the drill. The indexable drills have asymmetries in their geometries and loadings, and to incorporate the effect of such b

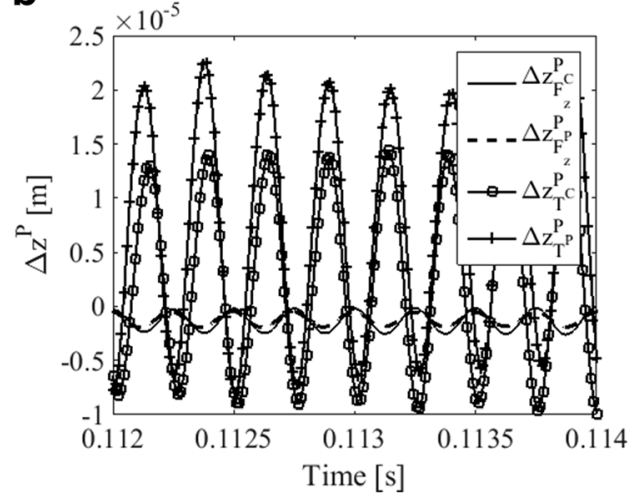

asymmetric designs, in the presented simulation, 16 frequency response functions are utilized. In addition, the effect of torsional vibrations on the time interval between two successive cuts (the delay term) is considered in the model. Nonlinearities posed by tool jump-outs and backward rotations are also considered. The studied example shows the importance of including effects of varying time delay on the dynamics of the drilling which is often ignored in analytical chatter prediction models for drilling.

The mentioned details can play a crucial role in drill design including designs of inserts, clamping systems for inserts, and the overall design of an indexable drill. For example, higher backward rotations in peripheral inserts may necessitate the application of a different coating type on the flank face of the peripheral insert compared to the coating of the central insert. The model predicts high variations in cutting forces, which is of great importance in analyzing and designing of the tools. The effects of these dynamic changes on the forces may need to be considered in the fatigue analysis.

Comparing the spectrum of the simulated and the measured tangential speed indicates that the model is able to predict the existence of chatter vibrations, frequency of the chatter, and its higher harmonics in
Fig. 12 The torsional vibration of the central insert (a) and the peripheral insert (b) due to axial forces and torques generated by the central and the peripheral inserts
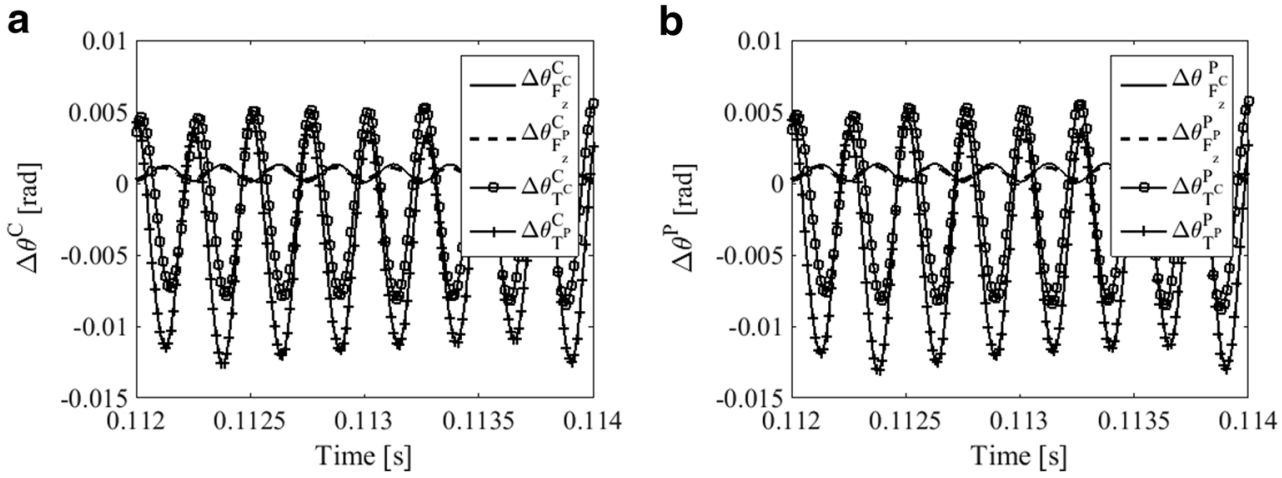


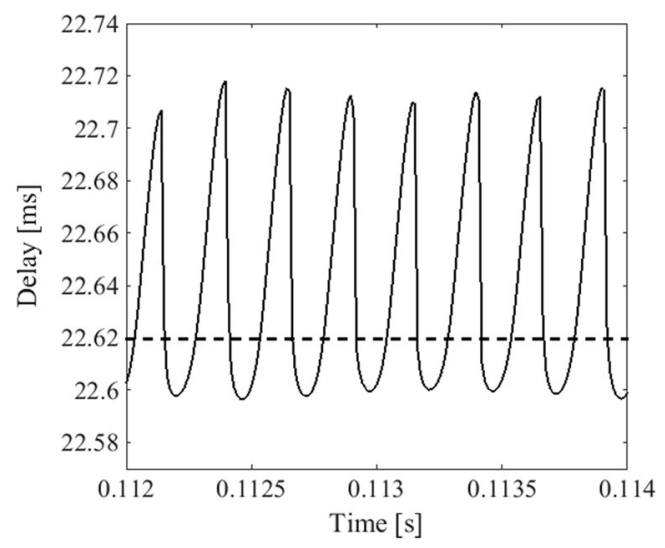

Fig. 13 Simulated delay term, the time between two successive cuts, for the central insert. The dashed line shows the time required for one full rotation of the spindle

frequency domain and amplitude of chatter vibrations in time domain. As it is shown in the previous sections, the patterns of dynamic cutting forces are not the same for central and peripheral inserts, which is important to consider from a design perspective. The model can be used to simulate the amplitude of vibrations on both inserts, which is useful for evaluating the new designs of drills. The developed model could be used for the selection between various drill designs, which considerably reduces the number of prototypes needed during the development of new indexable drills.

Acknowledgments This paper presents the results of a joint work between Sandvik Coromant and University West in Sweden. Funding of the project provided by Sandvik Coromant and the KK foundation is highly appreciated. Support from The Research School of Simulation and Control of Material affecting Processes $(\mathrm{SiCoMaP})$ is

a

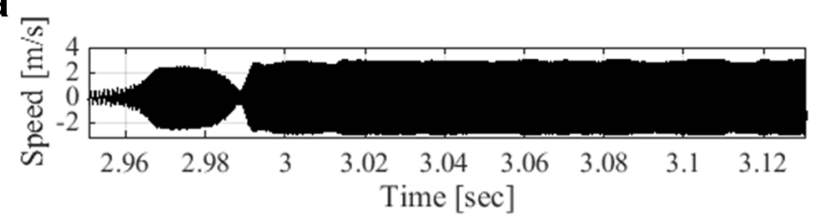

b

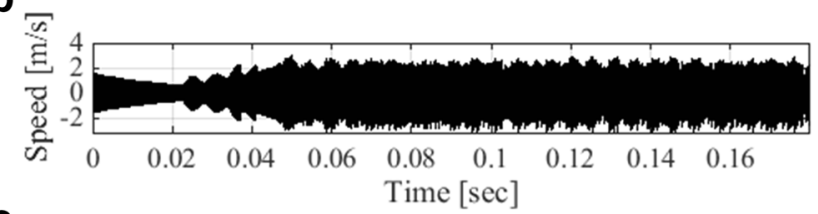

C

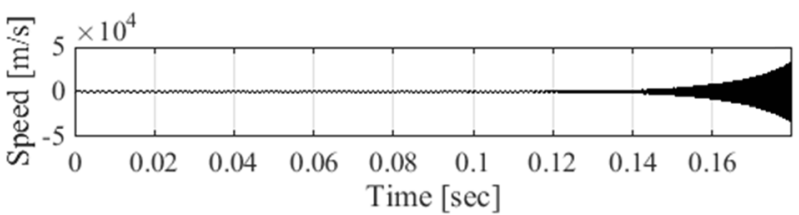

Fig. 14 Effect of constant time delay on simulation results. a Measurement. b Variable time delay. c Constant time delay gratefully acknowledged. Contributions made by Tommy Gunnarsson at Sandvik Coromant in conducting the experiments are greatly appreciated.

Open Access This article is distributed under the terms of the Creative Commons Attribution 4.0 International License (http:// creativecommons.org/licenses/by/4.0/), which permits unrestricted use, distribution, and reproduction in any medium, provided you give appropriate credit to the original author(s) and the source, provide a link to the Creative Commons license, and indicate if changes were made.

\section{References}

1. Tobias S (1964) Vibration of machine tools. Prod Eng 43(12):599 608

2. Merritt HE (1965) Theory of self-excited machine-tool chatter: contribution to machine-tool chatter research-1. J Eng Ind 87(4):447454

3. Brehl D, Dow T (2008) Review of vibration-assisted machining. Precis Eng 32(3):153-172

4. Paris H, Tichkiewitch S, Peigné G (2005) Modelling the vibratory drilling process to foresee cutting parameters. CIRP Ann Manuf Technol 54(1):367-370

5. Peigné G, Kamnev E, Brissaud D, Gouskov A (2005) Self-excited vibratory drilling: a dimensionless parameter approach for guiding experiments. Proc Inst Mech Eng B J Eng Manuf 219(1):73-84

6. Cheng K (2008) Machining dynamics: fundamentals, applications and practices, Springer Science \& Business Media

7. Dornfeld D, Lee D-E (2008) Precision manufacturing, Springer

8. Grzesik W (2008) Advanced machining processes of metallic materials: theory, modelling and applications, Elsevier

9. Liu X, Cheng K (2005) Modelling the machining dynamics of peripheral milling. Int J Mach Tools Manuf 45(11):1301-1320

10. Wojciechowski S, Chwalczuk T, Twardowski P, Krolczyk GM (2015) Modeling of cutter displacements during ball end milling of inclined surfaces. Arch Civil Mechan Eng 15(4):798-805

11. Quintana G, Ciurana J (2011) Chatter in machining processes: a review. Int J Mach Tools Manuf 51(5):363-376

12. Faassen R (2007) Chatter prediction and control for high-speed milling, Eindhoven University of Technology

13. Tlusty J, Polacek M (1963) The stability of machine tools against self-excited vibrations in machining. Int Res Prod Eng 1(1):465474

14. Tobias S, Fishwick W (1956) The vibrations of radial-drilling machines under test and working conditions. Proc Inst Mechan Eng 170(1):232-264

15. Narasimha K, Osman M, Chandrashekhar S, Frazao J (1987) An investigation into the influence of helix angle on the torque-thrust coupling effect in twist drills. Int J Adv Manuf Technol 2(4):91-105

16. Bayly PV, Metzler SA, Schaut AJ, Young KA (2001) Theory of torsional chatter in twist drills: model, stability analysis and composition to test. J Manuf Sci Eng 123(4):552-561

17. Astakhov V (2015) Drills: Science and Technology of Advanced Operations, CRC Press

18. Arvajeh T, Ismail F (2006) Machining stability in high speed drilling - part 2: time domain simulation of a bending-torsional model and experimental validations. Int J Mach Tools Manuf 46(12): 1573-1581

19. Arvajeh T, Ismail F (2006) Machining stability in high-speed drilling - part 1: modeling vibration stability in bending. Int J Mach Tools Manuf 46(12):1563-1572 
20. Roukema JC, Altintas Y (2006) Time domain simulation of torsional-axial vibrations in drilling. Int $\mathbf{J}$ Mach Tools Manuf 46(15):2073-2085

21. Roukema JC, Altintas Y (2007) Generalized modeling of drilling vibrations. Part I: time domain model of drilling kinematics, dynamics and hole formation. Int J Mach Tools Manuf 47(9):14551473

22. Roukema JC, Altintas Y (2007) Generalized modeling of drilling vibrations. Part II: chatter stability in frequency domain. Int J Mach Tools Manuf 47(9):1474-1485

23. Ahmadi K, Altintas Y (2013) Stability of lateral, torsional and axial vibrations in drilling. Int J Mach Tools Manuf 68:63-74

24. Ahmadi K, Savilov A (2015) Modeling the mechanics and dynamics of arbitrary edge drills. Int J Mach Tools Manuf 89:208-220

25. Parsian A, Magnevall M, Beno T, Eynian M (2015) “Time-domain modeling of torsional-axial chatter vibrations in indexable drills with low damping," in The 4th International Conference on Virtual Machining Process Technology, Vancouver
26. Rahman M, Seah K, Venkatesh V (1988) Performance evaluation of endrills. Int J Mach Tools Manuf 28(4):341-349

27. Andrew C, Tobias S (1961) A critical comparison of two current theories of machine tool chatter. Int J Mach Tool Design Res 1(4): 325-335

28. Altintas Y (2012) Manufacturing automation: metal cutting mechanics, machine tool vibrations, and $\mathrm{CNC}$ design, Cambridge University Press

29. Filiz S, Bediz B, Romero L, Ozdoganlar OB (2014) Three dimensional dynamics of pretwisted beams: a spectral-Tchebychev solution. J Sound Vib 333(10):2823-2839

30. Brandt A (2011) Noise and vibration analysis: signal analysis and experimental procedures, John Wiley \& Sons

31. Tlusty J, Ismail F (1981) Basic non-linearity in machining chatter. CIRP Ann Manuf Technol 30(1):299-304

32. Wiercigroch M (1997) Chaotic vibration of a simple model of the machine tool-cutting process system. J Vib Acoust 119(3):468-475 